\title{
V. The decomposition of water vapour by electric sparks
}

\section{Alfred Holt Jun. \& Edwin Hopkinson}

To cite this article: Alfred Holt Jun. \& Edwin Hopkinson (1908) V. The decomposition of water vapour by electric sparks, Philosophical Magazine Series 6, 16:91, 92-110, DOI: 10.1080/14786440708636491

To link to this article: http://dx.doi.org/10.1080/14786440708636491

册 Published online: 21 Apr 2009.

Submit your article to this journal

Џ Article views: 2

Q View related articles $\sqsubset$ 


\section{Aromatic Compounds.}

It is found that the possession of ring structure on the part of a compound corresponds with an extra contractionthat is to say, the atomic volumes in ringed molecules are always less than the volumes of similar atoms in straight chain compounds, so that the total molecular volume is on the whole less than that of a similar complex in the fatty series.

The relative volumes of atoms in the nuclei are the same as those in straight chain compounds.

Thus it is found that the volumes of benzene and hexamethylene are proportional to their valency numbers from the critical point downwards, so that $\mathrm{C}=4 \mathrm{H}$ as before.

The volumes of the atoms in aliphatic side chains are, however, the same as in the paraffins.

It has been found that the critical coefficients of benzene and its homologues manifest similar relations to those shown by the molecular volumes.

Note--It should be mentioned that Barlow and Pope take the view that the relative volumes of the atoms in the molecular complexes, aromatic as well as aliphatic, are always maintained and that the volume of an atom in a compound is always proportional to its fundamental valency.

Munieipal School of Technology, Victoria University, Manchester.

V. The Decomposition of Water Vapour by Electric Sparks. By Alfred Holt, Jun., and Edwin Hopkinson* *

THE decomposition of a compound gas such as watervapour, or carbon dioxide, by electric sparks, and the separation and arrangement of the resulting products about the electrodes, is of special interest since it may be expected to show how far the hypothesis of electrolysis in liquids is applicable to gases.

Almost half a century ago Perrot (Ann. Chim. et Phys. 1861, p. 161) showed that the decomposition of water-vapour took place along the entire path of the spark and not only in the neighbourhood of the electrodes, and that the gas collected from the anode contained an excess of oxygen, while that from the cathode contained an excess of hydrogen, their amounts being equivalent to the copper deposited in a voltameter placed in the same circuit. His experiments

* Communicated by the Authors. 
proved, therefore, that an electric current is conducted through water-vapour in a similar manner as through liquid water.

J. J. Thomson ('Recent Researches in Electricity and Magnetism,' Appendix), in repeating the experiments of Perrot, found that the pole at which the excess of oxygen or hydrogen appeared depended on the length of the spark, for when it was extremely short and resembling an are the hydrogen was found at the anode and the oxygen at the cathode; whereas with a long spark, the excess of hydrogen appeared at the cathode and the excess of oxygen at the anode. A critical position could be found between long and short sparks at which the excess of hydrogen was sometimes collected at the anode and sometimes at the scathode. I.t, under these circumstances, Leyden jars were introduced into the circuit, the hydrogen always appeared at the anode and the oxygen at the cathode, while the critical spark-length was found to be increased. This was explained by Thomson by supposing that the separation of the oxygen and hydrogen was the result of the motion of charged hydrogen towards one pole and oppositely charged oxygen towards the other, the charges on the molecules of the gases being different when the discharge resembled an are or spark.

In a separate series of experiments he showed that there was an alteration in the sign of the charges on the molecules of these gases when the discharge changed from an arc to a spark, or vice versa.

More recently, Chapman and Lidbury (J. C. S. Trans. 1902, p. 1301) noticed that the position in which the watervapour entered the spark had a marked effect on the separation of the products of decomposition, for the excess of oxygen always appeared at the pole situated furthest from the point at which the current of vapour entered. It followed, therefore, that a position could be found at which there was no separation, pure electrolytic gas being collected at either pole. They further observed that when the vapour entered near the anode, the amount of separation of the oxygen and hydrogen was very much less than when it entered near the cathode. Their experiments led to the conclusion that it was not possible to give a complete explanation of the phenomena by an hypothesis based solely on the theory of electrolysis in liquids.

While carrying out another investigation, one of us noticed that oxygen and hydrogen could be separated to a considerable extent by the difference between the rates at which they diffused through water-vapour at low pressure. 


\section{Messrs. A. Holt and E. Hopkinson on Decomposition}

This separation was well shown by the following experiment :-A stream of water-vapour at about $15 \mathrm{~mm}$. pressure was drawn into the tabe $\mathrm{B}$ (fig. 1), where it divided, one

Fig.1.

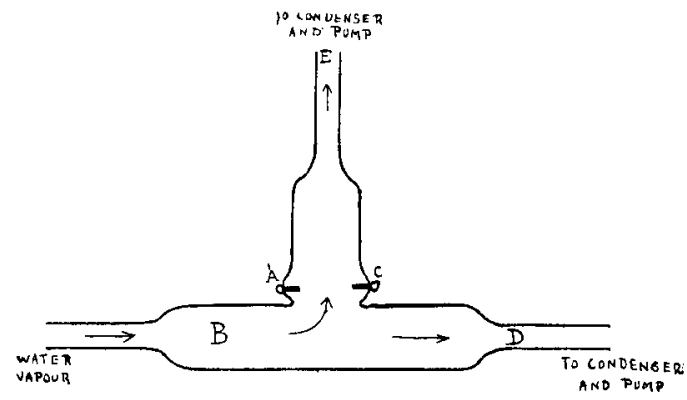

half passing straight on to a condenser $\mathrm{D}$ and pump, while the other half passed through the spark between $A$ and $C$, and on to a second condenser, E, and pump. Both condensers were kept at the same temperature, and both pumps were worked at approximately similar rates. Under these conditions it was found that the hydrogen produced by the spark diffused into the stream of vapour passing from $B$ to $D$, where it appeared in excess, while a proportionate excess of oxygen was collected from $\mathrm{E}$, since this gas could not readily diffuse back against the water-vapour current passing from $\mathrm{B}$ to $\mathrm{E}$.

\begin{tabular}{|c|c|c|c|}
\hline $\begin{array}{c}\text { No. of } \\
\text { experiment. }\end{array}$ & $\begin{array}{l}\text { Vol. of excess } \\
\text { of bydrogen col- } \\
\text { lected from } \mathrm{D} \text {. }\end{array}$ & $\begin{array}{l}\text { Vol. of excess } \\
\text { of oxygen col- } \\
\text { lected from } \mathrm{E} \text {. }\end{array}$ & $\begin{array}{l}\text { Total vol. of electro- } \\
\text { lytic gas collected } \\
\text { from } D+E \text {. }\end{array}$ \\
\hline 1 & $2 \cdot 14$ c.c. & 1.04 c.c. & $11 \cdot 2$ c.c. \\
\hline $\mathbf{2}$ & 1.94 c.c. & 0.94 c.c. & 105 c.c. \\
\hline 3. & $2 \cdot 20$ s.c. & 107 c.c. & $10 \cdot 0$ c.c. \\
\hline
\end{tabular}

It seemed possible that the separation of the oxygen and hydrogen in the spark might really be a diffusion-phenomenon, for most of the results obtained by Perrot and by Chapman and Lidbury can be explained by this hypothesis.

When electric sparks pass through water-vapour contained in an apparatus like that used by Chapman and Lidbury, a mixture of oxygen and hydrogen is produced in the path of 
the spark. The hydrogen, on account of its great power of diffusion, tends to become uniformly distributed throughout the apparatus, even if a rapid current of vapour is passing through it.

The distribution of the oxygen, however, depends far more on the water-vapour current; it will be divided according to the position of the entrance-tube. When this tube is in the neighbourhood of the cathode, the greater portion of the oxygen is driven out at the anode, the result being that an excess of oxygen is found at the anode and an equivalent excess of hydrogen at the cathode.

If this entrance-tube is brought to the anode, the hydrogen, on account of its power of diffusion, again tends to become equally distributed through all parts of the apparatus. The greater portion of the oxygen, however, is now swept out at the cathode, so that it appears in excess at that pole while hydrogen is found at the anode.

If equal quantities of oxygen are swept towards both poles, pure electrolytic gas should be collected from both anode and cathode, and Chapman and Lidbury found that this condition was reached when the entrance-tube was situated near the centre of the spark-gap.

The faster the stream of vapour passes through the apparatus the less easily does the oxygen diffuse against it, whereas the distribution of the hydrogen is almost unaffected, so the amount of separation of the decomposition products should increase as the stream of vapour becomes more and more rapid.

In order to investigate the truth of this view of the part played by diffusion, we have carried out a number of experiments with both water-vapour and carbon dioxide, for it should be impossible to obtain any separation of the oxygen and carbon monoxide produced by the passage of sparks through this latter gas, since both carbon monoxide and oxygen diffuse at almost similar rates, and would, consequently, become uniformly distributed in all parts of the apparatus.

In the first series of experiments, the discharge from an induction-coil with a large condenser was passed through a spark-tube of the shape shown in fig. 2 (p. 96). A rapid current of water-vapour entered the bulb D, which was blown in the centre of the spark-gap. The stream divided, any gas which might diffuse out of the spark was driven a way through the side-tube $\mathbf{E}$ to a condenser which was surrounded by a freezing-mixture, while the decomposition-products remaining in the path of the spark were swept by the stream 
of vapour through the two side-tubes $G$ and $H$, which communicated with another condenser also surrounded by a freezingmixture,

Fig. 2.

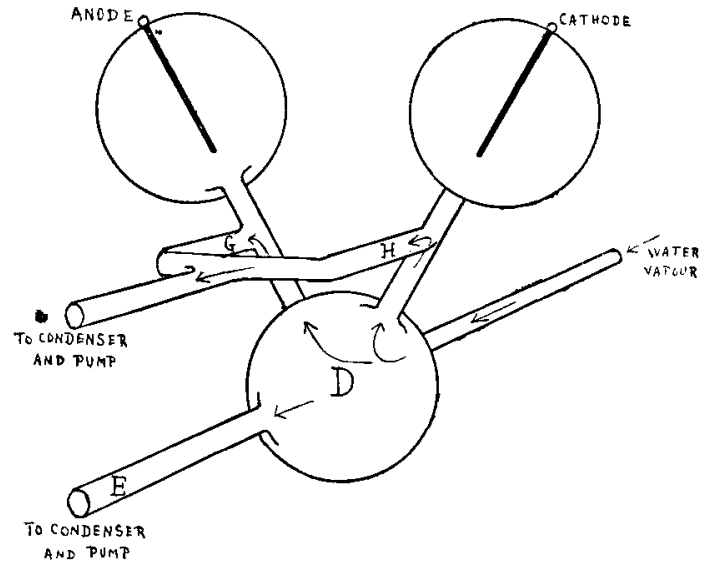

After condensation of the vapour in the condenser, the gases, which consisted of mixtures in different proportions of oxygen and hydrogen, were removed by automatic Sprengel pumps, and were collected separately and analysed in the same manner as in the experiments of Chapman and Lidbury.

A voltameter was placed in the circuit so that comparison could be made between the amount of decomposition of the water-vapour and the quantity of electricity passing in the spark.

The rate at which the water-vapour passed through the apparatus was varied, and it was noticed that when the current of vapour was slow the separation of the oxygen and hydrogen was small, but that it increased rapidly as the stream became faster, until practically pure hydrogen was collected from the diffusion-bulb $\mathrm{D}$.

If the separation of the oxygen and hydrogen is really a diffusion phenomenon, one would expect that with this apparatus the gas collected through $\mathrm{E}$ should contain an excess of hydrogen, while that from $G$ and $H$ should contain a proportionate excess of oxygen ; for it is improbable that any large amount of oxygen could diffuse back into the bulb $D$ against the rapid eurrent of water-vapour passing from $D$ to $G$ and rom $\mathrm{D}$ to $\mathrm{H}$. The faster the stream of vapour was passing, the less easily could the oxygen diffuse against it, and hence the larger the excess of hydrogen found in $\mathrm{D}$. 
of Water-Vapour by Electric Sparks.

The following results were obtained with this apparatus:-

\begin{tabular}{|c|c|c|c|c|c|c|c|}
\hline \multirow[b]{2}{*}{ 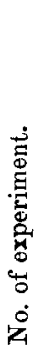 } & \multirow[b]{2}{*}{ 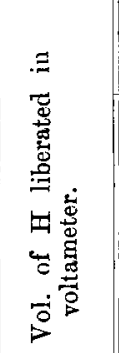 } & \multicolumn{3}{|c|}{$\begin{array}{l}\text { Excess of Hydrogen } \\
\text { from Bulb D. }\end{array}$} & \multicolumn{3}{|c|}{$\begin{array}{l}\text { Excess of Oxygen } \\
\text { from } G \text { and H. }\end{array}$} \\
\hline & & 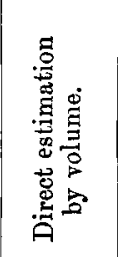 & 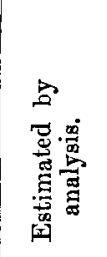 & 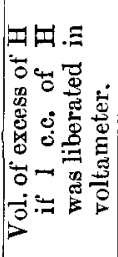 & 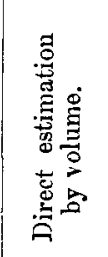 & 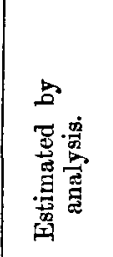 & 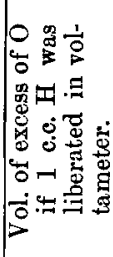 \\
\hline 1. & 0.545 c.c. & 6.06 c.c. & 6.05 c.c. & $11 \cdot 10$ c.c. & 2.96 c.c. & 2.89 c.c. & $5 \cdot 12$ c.c. \\
\hline 2. & 0.795 c.c. & 8.86 c.c. & $\ldots$ & $11 \cdot 14$ c.c. & 4.13 c.c. & $\ldots$ & $5 \cdot 19$ с.с. \\
\hline 3. & $1 \cdot 175$ c.c. & $7 \cdot 88$ c.c. & $\ldots$ & 6.70 c.c. & 3.87 c.c. & $\ldots$ & 3.30 c.c. \\
\hline 4. & 1.005 c.c. & 6.41 c.c. & 6.38 c.c. & $6 \cdot 35$ c.c. & $3 \cdot 16$ c.c. & $3 \cdot 14$ c.c. & $3 \cdot 12$ c.c. \\
\hline 6. & 0.312 c.c. & $5 \cdot 11$ c.c. & $5 \times 01$ c.c. & 16.06 c.c. & 2.52 c.c. & $\ldots$ & 8.07 c.c. \\
\hline
\end{tabular}

In three experiments the total gas collected from the bulb $D$ was carefully analysed in order to see whether the percentage of oxygen contained in it diminished as the stream of vapour became more and more rapid.

In the first experiment (No. 6) the stream of vapour was comparatively slow, and the ratio $\frac{\mathrm{O}_{2}}{\mathrm{H}_{2}}$ was found to be

$$
\frac{1 \cdot 274}{7 \cdot 564}=0 \cdot 169
$$

therefore the gas contained 16.9 per cent. oxygen.

In the second experiment (No. 2) the current of watervapour was more rapid, and the ratio $\frac{\mathrm{O}_{2}}{\mathrm{H}_{2}}$ was

$$
\frac{0 \cdot 34}{9 \cdot 54}=0 \cdot 035 \text {, }
$$

so that the gas contained only 3.5 per cent. oxygen.

In a third experiment (No. 5), in which the stream of vapour was extremely rapid, nearly pure hydrogen was obtained. These results are exactly what one would expect if the separation of the oxygen and hydrogen is a diffusionphenomenon. A number of experiments were next perPhil. Mag. S. 6. Vol. 16. No. 91. July 1908. 
formed with the same spark-tube, but a stream of carbon dioxide was substituted for the water-vapour.

The arrangement of the apparatus is shown in fig. 3 .

Fig. 3.

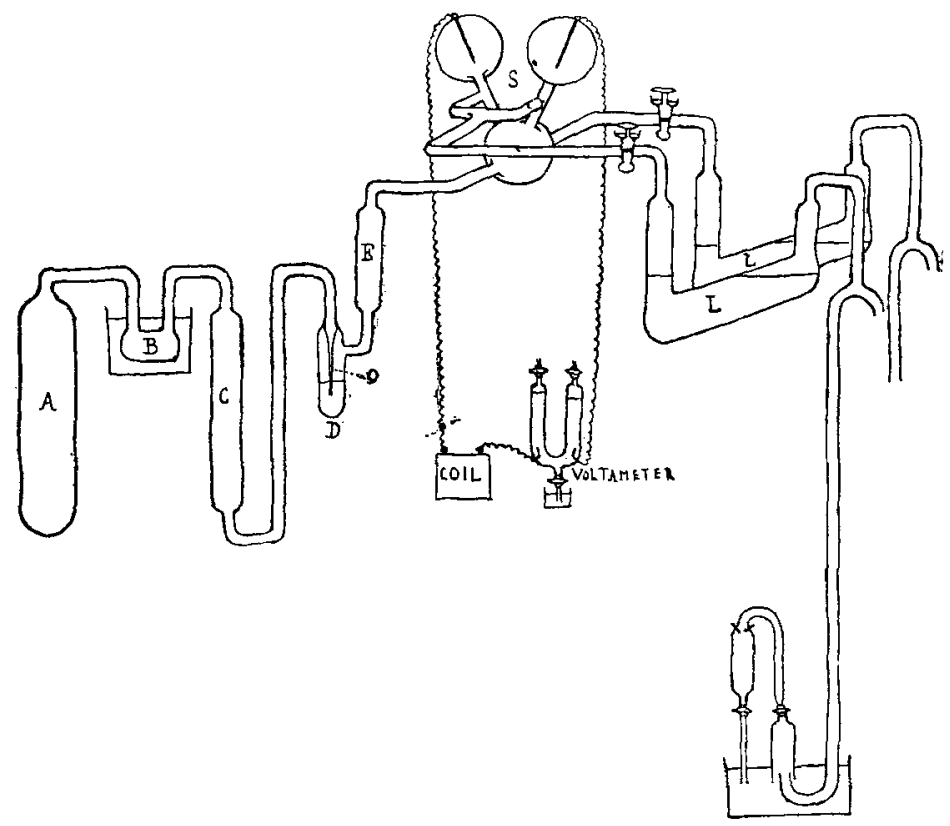

The carbon dioxide was generated by heating in an airbath, pure sodium bicarbonate, contained in the tube $A$.

The water produced by the decomposition of the bicarbonate was partly condensed in B, which was immersed in cold water, after which the gas was passed through a mixture of fused calcium chloride and anhydrous sodium carbonate contained in $\mathrm{C}$ so as to completely dry it. The dry gas next passed through a very fine capillary tube, $O$, dipping into concentrated sulphuric acid contained in the vessel $D$. The capillary tube was of such a bore that when there was practically a vacuum on one side of it and carbon dioxide at atmospheric pressure on the other, the gas would pass through at the rate of about five litres (at N.T.P.) per hour. This was about the mean rate of the water-vapour current in the previous experiments.

After bubbling through the concentrated sulphuric acid, any spray being removed by the glass-wool $\mathbf{E}$, the gas entered 
the spark-tube, where, as in the water-vapour experiments, it divided into two streams. After being sparked, the gas passed through the absorber $\mathrm{L}$, in which the carbon dioxide was removed by concentrated potash solution. The rosidual carbon monoxide and oxygen were then pumped off and analysed by explosion.

The quantity of electricity passing in the spark was again measured by a voltameter placed in the circuit.

Several experiments were carried out, but in no case conld the separation of the carbon monoxide and oxygen be detected, for the gas collected from the bulb $G$ and from $H$ and $K$ always contained these gases in the proportion to form carbon dioxide. The rate at which the current of carbon dioxide passed through the apparatus was varied by altering the diameter of the capillary tube $O$, but it was found to be entirely without effect except as regards the total amount of decomposition, which increased as the stream of gas became faster.

Since carbon monoxide and oxygen diffuse at practically the same rate, one would not expect to find any separation occurring in the spark, and the above results show that there is none.

The next series of experiments consisted of a repetition of those carried out by Chapman and Lidbury on the effect caused by the position in which the stream of gas entered the spark.

A stream of carbon dioxide was again substituted for the current of water-vapour.

The gas was allowed to enter the spark-tube at either the anode or cathode, or at any intermediate position, and the size and shape of the bulbs round the electrodes were also greatly varied, but in every experiment the products of decomposition consisted of carbon monoxide and oxygen in combining proportions.

No separation could be detected.

A further series of experiments were carried out in order to study the effect of passing a more rapid current of water-vapour through one end of a spark-tube than through the other. The apparatus employed is illustrated in fig. 4.

A stream of water-vapour passed along the tube B and divided, one portion passing through the bulb $\mathrm{A}$ to a condenser and pump, and the other passing through $\mathrm{C}$ to a second condenser and pump. The tube from A to $C$ tbrough which the spark passed had a bore of one millimetre.

\section{$\mathrm{H} 2$}




\section{Messrs. A. Holt and E. Hopkinson on Decomposition}

By altering the temperature of one of the condensers or by changing the speed of one of the pumps, the current of watervapour passing through $A$ could be made either faster or slower than that passing through $\mathrm{C}$.

The amount of separation of oxygen and hydrogen obtained with this apparatus was found to depend on the difference between the velocities of the two streams. When the more rapid current passed through the bulb containing the cathode, an excess of hydrogen was obtained at that pole, while oxygen appeared at the anode; but if the faster stream passed through the anode bulb, the poles at which the excesses of oxygen and hydrogen were collected were reversed.

Fig. 4.

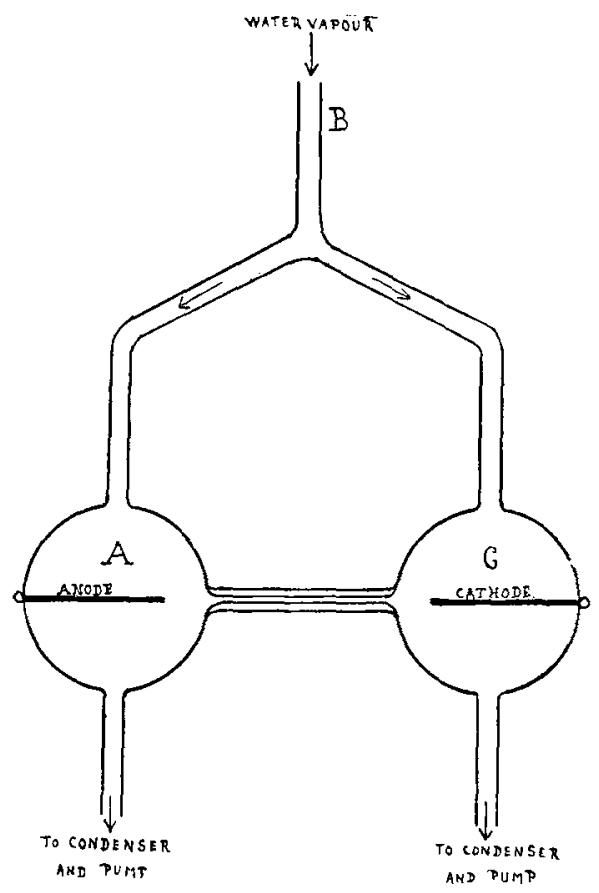

Further, the amount of the excesses of oxygen and hydrogen was much less when the more rapid stream of vapour passed through the anode bulb. 
of Water-Vapour by Electric Sparks.

The following details of an experiment will illustrate these observations:-

\begin{tabular}{|c|c|c|c|c|}
\hline \multicolumn{5}{|c|}{ 1. More rapid current through cathode bulb. } \\
\hline $\begin{array}{l}\text { Hydrogen } \\
\text { collected in } \\
\text { roltameter } \\
\text { in same } \\
\text { circuit. }\end{array}$ & $\begin{array}{l}\text { Excess of } \\
\text { hydrogen } \\
\text { from } \\
\text { cathode. }\end{array}$ & $\begin{array}{c}\text { Excess of hy- } \\
\text { drogen for } 1 \text { c.c. } \\
\text { hydrogen liber- } \\
\text { ated in volta- } \\
\text { meter. }\end{array}$ & $\begin{array}{l}\text { Excess of } \\
\text { oxygen } \\
\text { from } \\
\text { anode. }\end{array}$ & $\begin{array}{c}\text { Excess of } \\
\text { oxygen for } 1 \text { c.c. } \\
\text { hydrogen liber- } \\
\text { ated in volta- } \\
\text { moter. }\end{array}$ \\
\hline 3.055 c.c. & 4.529 c.c. & $1 \cdot 482$ c.c. & $2 \cdot 241$ c.c. & 0.733 c.c. \\
\hline \multicolumn{5}{|c|}{ 2. More rapid current through anode bulb. } \\
\hline $\begin{array}{l}\text { Hydrogen } \\
\text { collected in } \\
\text { voltameter } \\
\text { in sanie } \\
\text { circuit. }\end{array}$ & $\begin{array}{c}\text { Excess of } \\
\text { bydrogen } \\
\text { from } \\
\text { anode. }\end{array}$ & $\begin{array}{c}\text { Excess of hy- } \\
\text { drogen for } 1 \text { c.c. } \\
\text { hydrogen liber- } \\
\text { ated in volta- } \\
\text { meter. }\end{array}$ & $\begin{array}{c}\text { Excess of } \\
\text { oxygen } \\
\text { from } \\
\text { cathode. }\end{array}$ & $\begin{array}{l}\text { Excees of } \\
\text { oxygen for } 1 \text { c.c. } \\
\text { hydrogen liber- } \\
\text { ated in volta- } \\
\text { meter. }\end{array}$ \\
\hline 2.673 c.c. & 0.622 c.c. & 0.232 c.c. & 0.173 c.c. & 0.065 c.c. \\
\hline
\end{tabular}

These different results obtained with the same apparatus are easily explicable as a diffusion phenomenon, for when the current of water-vapour which passes down one limb is more rapid than that down the other, it is evident that there is a larger volume of gas in the quicker stream into which the hydrogen can diffuse, and since it becomes, or tends to become, equally distributed throughout the water-vapour, the greater part of it will be collected where there is the more rapid current. The oxygen can only be affected to an extent equal to one-sixteenth that of the hydrogen, so that very little more of it is found to pass into the faster than into the slower stream.

A consideration of these experiments leads to the conclusion that the products of decomposition of a compound gas are not arranged in such a manner that one constituent is liberated at the anode and the other at the cathode.

A homogeneous mixture is first formed in the path of the spark, and the separation is due to gasecus diffusion against the current of water-vapour. When both the decomposition products diffuse at nearly similar rates, there is no perceptible separation. 


\section{Messrs. A. Holt and E. Hopkinson on Decomposition}

Though many of the phenomena attending the decomposition of a gas by electric sparks can thus be readily explained by diffusion, this explanation, in its unmodified form, is insufficient to account both for the important fact observed by Thomson that when very short sparks are used the poles at which the excesses of oxygen and hydrogen appear are reversed, and for the interesting observation made by Chapman and Lidbury, that the total amount of watervapour decomposed and the extent of the separation of the decomposition-products is very much greater when the current of vapour enters the spark-tube in the neighbourhood of the cathode instead of near the anode.

When sparks are passed between platinum electrodes in water-vapour, some of the metal is shot or sprayed off the electrodes in the form of extremely minute particles which adhere to the surface of the glass, and gradually produce a metallic film on those portions of the spark-tube which immediately surround the anode and cathode. The amount of metal deposited from the anode is extremely small compared with that from the cathode.

The minute particles which constitute this metallic spray have in all probability a very powerful catalytic action, since they must closely resemble platinum-black, and the film which they form when deposited on the glass would also have, though in a lesser degree, the property of combining electrolytic gas.

It appeared to us that this metallic spray and deposit, with its catalytic action, must influence the amount of watervapour decomposed by the sparks, and might possibly account for the various phenomena not wholly explicable by the hypothesis of gaseous diffusion.

In order to study this catalytic action, it was necessary to carry out parallel experiments with platinum and some metal which did not give any perceptible spray under the influence of the spark, and which did not react chemically with watervapour when heated to a moderate temperature.

Aluminium seemed very suitable for this purpose as it does not readily oxidize in water-vapour, and no metallic film can be formed from it.

A series of spark-tubes of the shape shown in fig. $5, \mathrm{~A}$ and $B$, were used, the sole difference between them being the diameter of the bulbs surrounding the electrodes, which in type $A$ was $1 \mathrm{~cm}$., and in type $B 5 \mathrm{cms}$. In some tubes the electrodes were of aluminitum, and in others of platinum. With this latter metal various thicknesses of electrodes were tried in order to see whether the results were affected, for the thinner the electrode the hotter would the cathode become 
of Water-Vapour by Electric Sparks.

under the influence of the spark discharge, and the amount of metal shot off increases with rise of temperature.

Fig. 5.

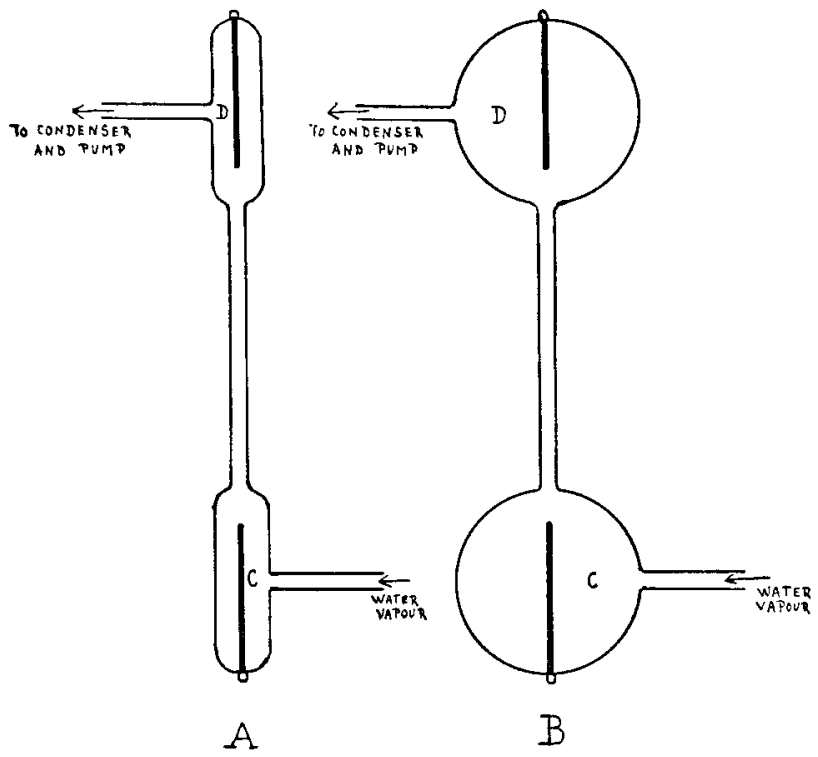

The stream of water-vapour at about $12 \mathrm{~mm}$. pressure entered the tubes at $\mathrm{C}$, and after being decomposed by the spark passed out at $\mathbf{D}$ to a condenser surrounded by a freezingmixture whence the electrolytic gas was removed by a pump, and estimated by explosion. The electrode at C or D could be made anode or cathode at will by simply reversing the current.

The experiments were carried out as follows:-

The whole apparatus being completely evacuated, a current of water-vapour, the velocity of which was measured by the volume of water collected in the condenser per hour, was passed through the spark-tube, and $\mathrm{C}$ was made the cathode.

After ten minutes' continuous sparking the current was switched off and the electrolytic gas produced was removed by the pump and estimated. D was then made the cathode, and sparks were passed for another ten minutes, when the resulting oxygen and hydrogen were pumped off and estimated as before. The ratio of the amount of the electrolytic gas obtained when the cathode was at $C$ to that when it was at $D$ could then be calculated.

The two observations were made as rapidly as possible so that the rate of the stream of water-vapour might be assumed to be the same in each case. No voltameter was placed in 


\section{Messrs. A. Holt and E. Hopkinson on Decomposition}

the circuit, but care was taken that the amount of electricity passing during each ten minutes of sparking was approximately the same.

Without altering the apparatus in any way or admitting air to it, a series of pairs of experiments were made in the manner just described.

The reason for doing this, and not cleaning off the metal deposited on the glass of the spark-tube during each of these experiments, was to see to what extent the metallic film, apart from the actual spray, exercised a catalytic influence. During each ten minutes' sparking the film would become thicker and denser, while the amount of spray round the cathode would remain fairly constant, since it only depends on the spark and the consequent heating of the electrode. If, then, the ratio of the amount of electrolytic gas collected when the cathode was at $C$ to that when it was at $D$ was found to alter through successive pairs of experiments, it would show that the metallic film exercised a catalytic influence apart from that of the spray round the heated cathode.

The following table gives the results of some of these experiments.

\begin{tabular}{|c|c|c|c|c|c|}
\hline $\begin{array}{l}\text { No. of } \\
\text { pairs of } \\
\text { experi- } \\
\text { ments. }\end{array}$ & Electrodes. & $\begin{array}{l}\text { Diameter of } \\
\text { bulbs round } \\
\text { electrodes. }\end{array}$ & $\begin{array}{c}\text { Vol. of } \\
\text { electrolytic } \\
\text { gas collected } \\
\text { in } 10 \text { mins. } \\
\text { when cathode } \\
\text { was at C. } \\
\text { A. }\end{array}$ & $\begin{array}{c}\text { Vol. of } \\
\text { electrolytic } \\
\text { gas collected } \\
\text { in } 10 \text { mins. } \\
\text { when cathode } \\
\text { was at D. } \\
\text { B. }\end{array}$ & $\begin{array}{c}\text { Ratio } \\
\mathbf{B} / \mathbf{A} .\end{array}$ \\
\hline $\begin{array}{l}1 . \\
2 . \\
3 .\end{array}$ & $\begin{array}{l}\text { Platinum } \\
\text { wire } 0.5 \mathrm{~mm} \text {. } \\
\text { diameter. }\end{array}$ & $1 \mathrm{~cm}$. & $\begin{array}{l}8.58 \text { c.c. } \\
8.09 \text { c.c. } \\
8.96 \text { c.c. }\end{array}$ & $\begin{array}{l}2.08 \text { c.c. } \\
1.62 \text { e.c. } \\
1.62 \text { c.c. }\end{array}$ & $\begin{array}{l}0.242 \\
0.201 \\
0 \cdot 181\end{array}$ \\
\hline $\begin{array}{l}4 . \\
5 . \\
6 .\end{array}$ & $\begin{array}{l}\text { Aluminium } \\
\text { wire } 0.5 \mathrm{~mm} \text {. } \\
\text { diameter. }\end{array}$ & $1 \mathrm{~cm}$. & $\begin{array}{l}2.44 \text { c.c. } \\
5.96 \text { c.c. } \\
7.17 \text { c.c. }\end{array}$ & $\begin{array}{l}2 \cdot 49 \text { c.c. } \\
6 \cdot 14 \text { c.c. } \\
7 \cdot 50 \text { c.c. }\end{array}$ & $\begin{array}{l}1.018 \\
1.031 \\
1.047\end{array}$ \\
\hline $\begin{array}{l}7 . \\
8 .\end{array}$ & $\begin{array}{l}\text { Platinum } \\
\text { wire I ram. } \\
\text { diameter. }\end{array}$ & $1 \mathrm{~cm}$. & $\begin{array}{l}2.58 \text { e.c. } \\
1.99 \text { c.e. }\end{array}$ & $\begin{array}{l}178 \text { c.c. } \\
1.32 \text { c.c. }\end{array}$ & $\begin{array}{l}0.690 \\
0.663\end{array}$ \\
\hline $\begin{array}{r}9 . \\
10 .\end{array}$ & $\begin{array}{l}\text { Platinum } \\
\text { wire } 0.5 \mathrm{~mm} . \\
\text { diameter. }\end{array}$ & $5 \mathrm{cms}$. & $\begin{array}{l}3.18 \text { c.c. } \\
3.14 \text { c.c. }\end{array}$ & $\begin{array}{l}2.94 \text { c.c. } \\
2.87 \text { c.c. }\end{array}$ & $\begin{array}{l}0.924 \\
0.914\end{array}$ \\
\hline
\end{tabular}


In the above table, experiments 1-3 when compared with 4-6 show the enormous effect the metal composing the electrodes exerts on the amount of electrolytic gas obtained when the stream of water-vapour enters the spark-tube at the anode and cathode respectively. Experiments 1-3 compared with 7-8 show the difference between thick and thin electrodes. In experiments 7-8, where the electrodes are thick and therefore become only slightly heated, there is a very small amount of spray, and consequently the difference in the amount of gas collected when the vapour enters at the cathode compared with that when it enters at the anode is smaller than in experiments $1-3$.

Experiments 1-3 and 9-10 show the effect of large and small bulbs round the electrodes. It will be noticed that when the bulbs are large, the effect is the same as when the electrodes are very thick. This difference between the amount of gas collected when the water-vapour enters at the anode or cathode can be explained by the catalytic action of the platinum spray.

In the first experiment of any series the spark-tube is clean and $C$ is made the cathode, as already mentioned. The vapour enters at the cathode, is partially decomposed by the spark and passes over the anode on its way out of the tube at 1 . The amount of spray and heating at the anode being negligible, and the surrounding glass being clean, no recombination of the electrolytic gas produced in the spark takes place.

$\mathrm{D}$ is next made the cathode; the electrolytic gas produced in the spark passes over its heated surface, from which particles of metal are being shot off; and some recombination of the oxygen and hydrogen occurs; consequently a smaller amount is collected than when the cathode was at $C$.

When the electrodes are thick the heating of the cathode is less, and a smaller amount of metal is shot off : there is therefore less recombination; and if a very thick cathode is used there may be little difference between the amounts of gas collected according as this pole is at $\mathrm{C}$ or $\mathrm{D}$.

It will be noticed in the table that in the case of platinum each successive pair of experiments gives a lower value for the ratio $B / A$, that is to say the amount of recombination increases every time D is made the cathode. Since the amount of spray shot off the cathode does not vary from one experiment to the next, this increase of recombination must result from the catalytic action of the metallic film which is deposited on the walls of the tube. This film becomes denser 


\section{Messrs. A. Holt and E. Hopkinson on Decomposition}

with each experiment, and so presents a larger active surface to the electrolytic gas, as it passes over it.

When the bulbs round the electrodes are of large diameter, less oxygen and hydrogen is combined by the metallic particles, since there is a larger volume of water-vapour into which the electrolytic gas produced by the spark can diffuse, and so escape the catalytic action.

As the difference between the behaviour of aluminium and platinum when used as electrodes during the decomposition of water-vapour by electric sparks seemed of considerable interest, we were led to examine the action of other metals as well.

A number of spark-tubes of the shape shown in fig. $4 \mathrm{~A}$ were used, and the pairs of experiments were carried out exactly as already described. As it was not possible to obtain all the metals in wires of equal thickness, the values for the ratio B/A for one metal are not strictly comparable with those for another.

The following tables give a summary of the results obtained with different metals :-

\begin{tabular}{|c|c|c|c|}
\hline Electrodes. & $\begin{array}{c}\text { Vol. of electrolytic } \\
\text { gas collected in } \\
10 \text { mins. when } \\
\text { cathode was at } \mathrm{C} . \\
\text { A. }\end{array}$ & $\begin{array}{c}\text { Vol. of electrolytic } \\
\text { gas collected in } \\
10 \text { mins. when } \\
\text { cathode was at D. } \\
\text { B. }\end{array}$ & $\begin{array}{l}\text { Ratio } \\
\mathbf{B} / \mathbf{A} \text {. }\end{array}$ \\
\hline $\begin{array}{l}\text { Gold } \\
\text { wire } 0.5 \mathrm{~mm} \text {. } \\
\text { diameter. }\end{array}$ & $\begin{array}{l}6.38 \text { c.c. } \\
8.12 \text { c.c. } \\
5.66 \text { c.c. }\end{array}$ & $\begin{array}{l}7.79 \text { c.c. } \\
7.32 \text { e.c. } \\
4.27 \text { c.c. }\end{array}$ & $\begin{array}{l}0.929 \\
0.801 \\
0-754\end{array}$ \\
\hline $\begin{array}{l}\text { Silver } \\
\text { wire } 1.0 \mathrm{~mm} \text {. } \\
\text { diameter. }\end{array}$ & $\begin{array}{l}8.41 \text { c.c. } \\
7.94 \text { c.s. } \\
7.84 \text { c.c. }\end{array}$ & $\begin{array}{l}8 \cdot 18 \text { c.c. } \\
7 \cdot 71 \text { c.c. } \\
7.61 \text { c.c. }\end{array}$ & $\begin{array}{l}0974 \\
0971 \\
0970\end{array}$ \\
\hline $\begin{array}{l}\text { Copper } \\
\text { wire } 10 \mathrm{~mm} \text {. } \\
\text { diameter. }\end{array}$ & $\begin{array}{l}7 \cdot 36 \text { c.c. } \\
8 \cdot 24 \text { c.c. }\end{array}$ & $\begin{array}{l}6.88 \text { c.c. } \\
7.52 \text { c.c. }\end{array}$ & $\begin{array}{l}0936 \\
0.912\end{array}$ \\
\hline $\begin{array}{l}\text { Iron } \\
\text { wire } 0.3 \mathrm{~mm} \text {. } \\
\text { diameter. }\end{array}$ & $\begin{array}{l}5.09 \text { c.c. } \\
5.22 \text { c.c. }\end{array}$ & $\begin{array}{l}5.41 \text { c.c. } \\
5.44 \text { c.c. }\end{array}$ & $\begin{array}{l}1.062 \\
1.042\end{array}$ \\
\hline $\begin{array}{l}\text { Niokel } \\
\text { wire } 0.3 \mathrm{~mm} . \\
\text { diameter. }\end{array}$ & $\begin{array}{l}5.83 \text { с.е. } \\
5.75 \text { c.e. }\end{array}$ & $\begin{array}{l}5.87 \text { c.c. } \\
5.95 \text { c.c. }\end{array}$ & $\begin{array}{l}1.006 \\
1.035\end{array}$ \\
\hline
\end{tabular}


of Water-Vapour by Electric Sparles.

\begin{tabular}{|c|c|c|c|}
\hline Electrodes. & $\begin{array}{c}\text { Vol. of electrolytic } \\
\text { gas collected in } \\
10 \text { mins. when } \\
\text { cathode was at C. } \\
\text { A. }\end{array}$ & $\begin{array}{l}\text { Vol. of electrolytic } \\
\text { gas collected in } \\
10 \text { mins. whon } \\
\text { cathode was at D. } \\
\text { B. }\end{array}$ & $\begin{array}{l}\text { Ratio } \\
\mathbf{B} / \mathbf{A} .\end{array}$ \\
\hline $\begin{array}{l}\text { Cadmiume } \\
\text { strips of foil } \\
1.0 \mathrm{~mm} . \\
\text { diameter. }\end{array}$ & $\begin{array}{l}6.04 \text { c.c. } \\
6.41 \text { c.c. }\end{array}$ & $\begin{array}{l}6.50 \text { c.c. } \\
655 \text { c.c. }\end{array}$ & $\begin{array}{l}1.073 \\
1093\end{array}$ \\
\hline $\begin{array}{l}\text { Zinc } \\
\text { strips of foil } \\
1.5 \mathrm{~mm} . \\
\text { diameter. }\end{array}$ & $\begin{array}{l}4.65 \text { с.с. } \\
4.59 \text { с.c. }\end{array}$ & $\begin{array}{l}4.70 \text { c.c. } \\
4.95 \text { c.c. }\end{array}$ & $\begin{array}{l}1.058 \\
1.077\end{array}$ \\
\hline $\begin{array}{l}\text { Tantallum } \\
\text { filament from } \\
\text { lamp. }\end{array}$ & $\begin{array}{l}4 \cdot 70 \text { c.c. } \\
4 \cdot 68 \text { c.c. }\end{array}$ & $\begin{array}{l}4.96 \text { c.c. } \\
4.52 \text { c.c. }\end{array}$ & $\begin{array}{l}1 \cdot 056 \\
1 \cdot 108\end{array}$ \\
\hline $\begin{array}{l}\text { Magnesium } \\
\text { wire } 0.5 \mathrm{~mm} . \\
\text { diameter. }\end{array}$ & $\begin{array}{l}4: 39 \text { c.c. } \\
4.39 \text { c.c. }\end{array}$ & $\begin{array}{l}4.75 \text { c.c. } \\
4.71 \text { e.c. }\end{array}$ & $\begin{array}{l}1.162 \\
1.07 t\end{array}$ \\
\hline $\begin{array}{l}\text { Palladium } \\
\text { wire about } \\
0.4 \mathrm{~mm} . \\
\text { diameter. }\end{array}$ & $\begin{array}{l}8.54 \text { c.c. } \\
0.89 \text { c.c. } \\
0.56 \text { c.c. }\end{array}$ & $\begin{array}{l}0.99 \text { c.c. } \\
0.31 \text { c.c. } \\
0.28 \text { c.c. }\end{array}$ & $\begin{array}{l}0 \cdot \mathbf{i} 16 \\
0 \cdot 352 \\
0.510\end{array}$ \\
\hline $\begin{array}{l}\text { Rhodium } \\
\text { wire about } \\
1.0 \mathrm{~mm} . \\
\text { diameter. }\end{array}$ & $\begin{array}{l}2.84 \text { c.c. } \\
1.50 \text { c.c. } \\
2.81 \text { c.c. }\end{array}$ & $\begin{array}{l}1 . \$ 4 \text { c.c. } \\
0.79 \text { с.c. } \\
0.95 \text { c.c. }\end{array}$ & $\begin{array}{l}0648 \\
0.464 \\
0 \cdot 340\end{array}$ \\
\hline $\begin{array}{l}\text { Ruthenium } \\
\text { small buttons } \\
\text { about } 3 \mathrm{~mm} . \\
\text { diameter. }\end{array}$ & $\begin{array}{l}2 \cdot 63 \text { c.c. } \\
2 \cdot 51 \text { c.c. }\end{array}$ & $\begin{array}{l}2.23 \text { c.c. } \\
2.18 \text { c.c. }\end{array}$ & $\begin{array}{l}0.845 \\
0.803\end{array}$ \\
\hline $\begin{array}{l}\text { Osmium } \\
\text { flament } \\
\text { from "Osmi" } \\
\text { Jamp. }\end{array}$ & $\begin{array}{l}7 \cdot 34 \text { c.c. } \\
6 \cdot 75 \text { c.c. } \\
5 \cdot 36 \text { c.c. }\end{array}$ & $\begin{array}{l}5.05 \text { c.c. } \\
3.62 \text { c.c. } \\
3.35 \text { c.c. }\end{array}$ & $\begin{array}{l}0 \cdot 685 \\
0.536 \\
0 \cdot 6.25\end{array}$ \\
\hline $\begin{array}{l}\text { Iridium } \\
\text { wire about } \\
\text { 1.0 mm. } \\
\text { diameter. }\end{array}$ & $\begin{array}{l}6.34 \text { c.c. } \\
5.43 \text { c.c. } \\
6.38 \text { c.c. }\end{array}$ & $\begin{array}{l}0.71 \text { c.c. } \\
0.59 \text { e.c. } \\
0.57 \text { c.c. }\end{array}$ & $\begin{array}{l}0 \cdot 112 \\
0 \cdot 108 \\
0090\end{array}$ \\
\hline
\end{tabular}




\section{Messrs. A. Holt and E. Hopkinson on Decomposition}

It will be seen from these tables that all those metals which oxidize when heated in air behave like aluminium. They give no spray and cause no recombination of the electrolytic gas produced by the spark. They do not appear to be oxidized by the water-vapour, but possibly a very thin skin of oxide is formed which prevents any metal being shot off the cathode, for several of them have been shown by Crookes (Proc. Roy. Soc. 1891 , vol. l. p. 88) to disintegrate in other gases.

Those metals which do not oxidize when heated in air to a moderate temperature, or which form a volatile oxide as in the case of osmium, behave, with the exception of silver and palladium, exactly like platinum. They disintegrate in watervapour and bring about more or less recombination of the electrolytic gas. Silver, though spraying readily, does not appear to combine oxygen and hydrogen. Palladium behaves exceptionally, for the ratio $B / A$ is found to steadily increase in each successive pair of experiments, instead of decreasing, as in the case of the other metals.

When this metal is in a state of very fine subdivision (palladium black), it is known to exert intense catalytic action on a mixture of oxygen and hydrogen. The metal rapidly becomes heated through the energy with which these gases are combined on its surface.

During the experiments with electrodes of this metal, it was noticed that the film deposited on the tube about $D$ became heated when $\mathrm{C}$ was the cathode, a phenomenon not observed in the case of any other metal; and though the amount of gas collected when $D$ was the cathode was found to diminish in each successive experiment, yet when $\mathrm{C}$ was the cathode it was found to diminish far more rapidly, especially at first, and hence caused the increase in the ratio $B / A$. As the film around D became heated, it was probable that the steady diminution in the amount of gas collected in each experiment when $C$ was the cathode was the result of recombination. To see if this was the case a series of experiments was carried out in exactly the same manner and with the same spark-tube, only when $C$ was the cathode, the metallic film round $\mathrm{D}$ was kept cold by water so as to prevent, as far as possible, any catalysis. The results then obtained were in exact agreement with the other platinum metals (tabie, p. 109).

The observations of Chapman and Lidbury that the degree of separation of the oxygen and hydrogen is less when the stream of water-vapour enters the spark near the anode than near the cathode can now receive a complete explanation.

When the vapour enters near the anode the greater part of 


\begin{tabular}{|c|c|c|c|}
\hline $\begin{array}{c}\text { No. of } \\
\text { Experiment. }\end{array}$ & $\begin{array}{c}\text { Volume of electrolytic } \\
\text { gas collected in } \\
\text { mins. when cathode } \\
\text { was at C. } \\
\text { A. }\end{array}$ & $\begin{array}{c}\text { Volume of electrolytic } \\
\text { gas collected m } \\
\text { mins. when cathode } \\
\text { was at D. } \\
\text { B. }\end{array}$ & $\begin{array}{c}\text { Ratio } \\
\mathrm{B} / \Lambda .\end{array}$ \\
\hline 1. & 6.739 c.c. & 2.607 c.c. & 0.386 \\
2. & 6.293 c.c. & 0.644 c.c. & 0.102 \\
3. & 6.125 c.c. & 0.371 c.c. & 0.060 \\
4. & 6.237 c.c. & 0.317 c.c. & 0.051 \\
\hline
\end{tabular}

the oxygen is swept towards the cathode, where it appears in excess, while the hydrogen is equally distributed between the two poles. A considerable quantity of the electrolytic gas passing over the cathode is, however, recombined there, so that less oxygen is left to appear in excess at that pole, and the hydrogen collected at the anode is proportionately diminished.

If the point of entry of the stream of vapour is near the cathode, a volume of oxygen equal to that which in the former case passed over this electrode, and was partially recombined, is now driven out at the anode, but its amount is not sensibly diminished there, since hardly any recombination takes place near this latter pole.

An explanation of the results obtained by Thomson can also be given, though the conditions in his experiments and in ours were somewhat different, since his steam was at atmospheric pressure, whilst our water-vapour was at about $12 \mathrm{~mm}$. pressure, and the amount of metal shot off the cathode, and hence the extent of catalysis, increases as the pressure decreases. The cathode is surrounded by particles of metal which exert a catalytic action on electrolytic gas, so that a zone of recombination is found around that pole; and one of us has already pointed out that if a homogeneous mixture of oxygen and hydrogen (as is found in the path of the spark) is produced inside such a zone, an excess of hydrogen may be expected outside it, while the oxygen becomes concentrated within (Phil. Mag. 1907, vol. xiii. p. 630).

If the electrodes are close together, almost the whole spark may be inside this recombination zone; and as, under these conditions, the gas swept through the cathode by the watervapour current will chiefly consist of that portion within the zone, an excess of oxygen should be found at the cathode, and a proportionate excess of hydrogen at the anode. When the spark is long, the greater portion of the electrolytic gas 
is produced outside the zone. The water-vapour enters at the centre of the spark; and if no recombination occurs near the cathode, equal quantities of oxygen will be swept towards each pole, and the hydrogen being uniformly distributed, pure electrolytic gas would be collected at both anode and cathode.

But recombination is taking place near the cathode, and consequently some of the electrolytic gas is removed there, so that a smaller quantity of oxygen is swept out at that pole than at the anode. The hydrogen, however, still tends to become distributed uniformly thronghout the apparatus, so that it now appears in excess at the cathode.

The experiments described in this paper lead us to the conclusion that when electric sparks pass through a compound gas such as water-vapour or carbon dioxide, the separation and arrangement of the decomposition products is not an electrical phenomenon, but results from gaseous diffusion. The hypothesis of electrolysis in liquids is therefore inapplicable.

The University, Manchester.

\section{Interaction of Dynamical Systems.} By R. Hargreaves*.

T $F$ there are two groups of coordinates $g$ and $\chi$ with corre1 sponding velocities $\dot{q}$ and $\dot{\chi}$, the kinetic energy of a system embracing both groups generally contains terms which are products of $\dot{q}$ and $\dot{\chi}$, as well as functions quadratic in the velocities of the separate groups; and the productterms give a mutual or composite action of the groups in an explicit way. This is also the case when the kinetic energy is expressed in terms of the momenta. But if the velocities of one group and the momenta of the other are used, it is characteristic that the energy shall appear as a sum of detached quadratics, and all trace of composite action is lost.

It is proposed to deal with this and other cases where a mutual action is concealed. For the case stated a kinetic potential of mixed type is introduced, i.e. one involving the velocities of one group and the momenta of the other. It is clear that when coordinates of the second group are absent and the momenta invariable, we have the problem of ignored coordinates, which therefore appears as a special case.

$\S 1$. Potential energy in the form of a function of coordinates only may be omitted, as its presence or absence does not affect the questions considered. A kinetic energy

* Communicated by the Author. 